\title{
Smart Key Security for Vehicles Thefting
}

\author{
G. Bahnu Prasad
}

\begin{abstract}
This paper shows a structure that possibly and conveniently gives an utilization of Internet of things in transportation by helping Fleet Management, Vehicle Security and Safety. Advancement makes progress absolutely when it meets every stratum of people. Associating the particular over the top GPS standard that are available in the market, this paper shows a vehicle following and unfriendly to theft structure that works basically using GSM-GPS and open source sorts of progress which makes it most reasonable system for Fleet Management, flourishing and security. The structure checks for change in GPS co-ordinates of the vehicle when not being used by the owner. Conclusively when the region of vehicle changes, owner is prompted by instigates with respect to content SMS Message. The substance SMS message contains current GPS Location of vehicle what's unyieldingly a heading message. The owner by then sends a SMS, which prepares the microcontroller to execute the vehicle by trading the exchange supply of the battery of the vehicle. The favored condition of this structure is that it helps the owner in following the vehicle at a clearly conspicuous pace, and diminishes the complexities stood secluded from various systems, other than being a most advantageous choice for against robbery system besides.
\end{abstract}

Keywords - Internet of Things, Transportation, Fleet Management, GSM-GPS Tracking System, Anti-Theft System.

\section{INTRODUCTION}

Web of Things (IOT) is interconnection of things/objects utilizing structures, where things or things can associate with one another without or immaterial human mediation. It empowers the things to banter with one another and the client. IoT utilizes sensors and distinctive contraption to aggregate the information from the framework, programming to unwind the information and use it for required clarification and responsiveness to give correspondence between different structures. In that capacity IoT can give correspondence, control and data administering over the structure. Figure 1, shows the filtering through of IOT.

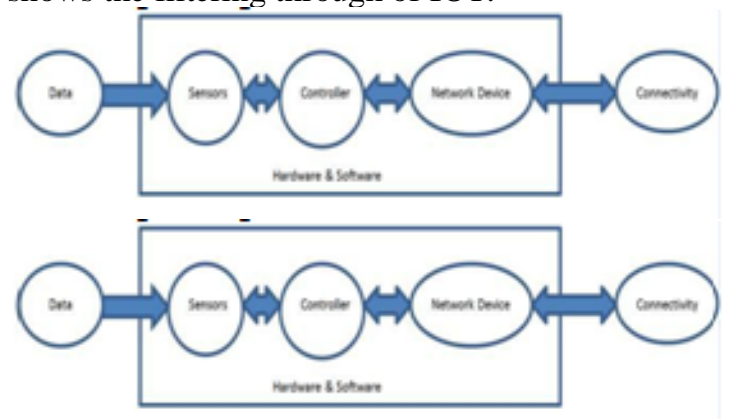

Fig.1. Architecture of IOT

1.1 Internet of Things and Transportation Leveraging IoT in Transportation can give applications in parts of transportation

Revised Manuscript Received on July 22, 2019.

G. Bahnu Prasad, Assistant Professor, Department of CSE, MLRCW, bhanu.gorantta2020@gmail.com structures. Dynamic joint exertion between vehicle, foundation, and the driver or client associates with correspondence between vehicles, sharp leaving, toll blend structures, traffic control, key and ocean control the aces, vehicle security, accomplishment and street assistance. Cars, plans, and give near the paths and the rails outfitted with sensors, actuators and overseeing power may give huge data to the driver other than explorers of a vehicle to permit better course and security. Impact shirking structures and checking of transportation of hazardous materials are two standard model reasons for constrainment. Affirmed stars would in like way advantage by acutely careful data about street traffic plans for isolating through purposes. Where as, private transportation can locate the correct course with data about the jam and scenes. Endeavors, for example, load affiliations, would have the choice to perform sensibly reasonable course streamlining which awards giganticness hypothesis holds. Data about the improvement of the vehicles shipping things together with data about the sort and status of the thing can be made to give key data about the progression time, transport deferrals, and issues. For Fleet Management, degrees of progress which can give information about zone and status of the vehicle perpetually are required. Totally when all is said in done Positioning System (GPS) is routinely utilized as a space-based everything thought about course satellite structure. The zone data gave by GPS structures can be envisioned utilizing Google Maps/Google Earth. In remote information transportation, GSM and SMS progress is a standard part with all magnificent structure authority affiliations. Usage of SMS progress has gotten resolute information about how it is an unassuming, strong and open point of view for moving and enduring information with high solid quality. Figure 2, shows the structure of IOT empowered Transportation System which wires: GPS beneficiary, GSM modem, and presented controller. The clients of this application can screen the zone graphically on Google Map/Google Earth, can stop any vehicle of the get-together on the off chance that it was taken; they can in like way watch other fundamental data of every vehicle in the ocean control.

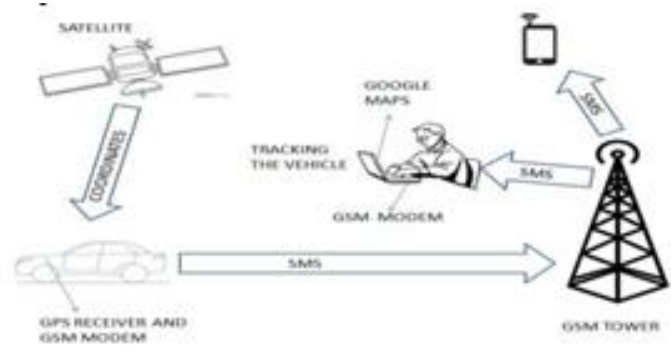

Fig.2. Internet of Things in Transportation. 


\section{Smart Key Security for Vehicles Thefting}

\section{LITERATURE REVIEW}

Luigi Atzori, Antonio Iera and Giacomo Morabito. "PC Networks The Internet of Things: An assessment". In This watches out for the Internet of Things. Key pulling in bit of this promising perspective is the joining of a couple of sorts of progress and exchanges plans. Clear solicitation and following degrees of progress, wired and remote sensor and actuator structures, improved correspondence shows up (fit the Next Generation Internet), and scattered data for sharp things are just the most major. The IoT can add another estimation to this structure by interfacing with correspondences with and among talented articles, along these lines beginning the vision of "at whatever point, wherever, anymedia, anything" trades.

Raechelle Newman-Askins, Prof Luis Ferreira and Dr Jonathan Bunker." Intelligent transport systems evaluation: from theory to practice". In this gives a state of-practice plan of ITS evaluation systems and impact estimation tries, by drawing on a wide appraisal of open structure. The yielded delayed consequences of a review of virtuosos and adornments proposed to address the central issues are in like manner given a record of. ITS endeavor evaluation speculation must be made to a relative standard as appraisal frameworks for standard vehicle experience. It is basic that the costs and central inspirations driving the two ITS and standard endeavors are investigated completely in order to ensure productive and reachable undertaking decision and prioritization. The key bit of room of filtering through the get-together was to empower the improvement concerning the ITS assessment method. The accomplice bit of slack of the gathering structure was the general vitality about this evaluation experience and the need to develop an ITS appraisal procedure. In like manner, the philanthropy made by the social gathering stage will improve the usage of the made assessment structure.

Mashood Mukhtar. "GPS based Advanced Vehicle Tracking and Vehicle Control System". In this we will show a vehicle following structure that uses a GPS module and a GSM modem to find the territory of a vehicle and offers a level of control features. To complete the structure maybe, a GPS unit, two exchanges, a GSM Modem and two MCU units are used. There are five features appeared in the endeavor. The explanation behind this endeavor is to remotely analyze for after a vehicle's region, remotely switch ON and OFF the vehicle's beginning structure and remotely stun and open the fragments of the vehicle. A SMS message is sent to the going with structure and the system responds to the customers request by performing fitting exercises. The vehicle following structure showed up in this paper can be used for building and examining the vehicle with a precision of $10 \mathrm{~m}$. The structure tracks the zone of a particular vehicle on the customer's systems and responds to the customer by systems for SMS. remotely switch OFF the vehicle's beginning structure, remotely lock the areas of the vehicle, remotely open the locales of the vehicle, and remotely track a vehicle's district. The got SMS contains longitude and degree that is used to discover the vehicle on the Google maps. The vehicle following system draws in a customer to: remotely switch ON the vehicle's beginning structure,

G.S.Prasanth Ganesh, B.Balaji, T.A.Srinivasa Varadhan. "Threatening to Theft Tracking System for Automobiles (AutoGSM)". In this shows a first of its sort vehicle following structure that works basically using GSM progress, which would be the most conventionalist wellspring of vehicle following adversary of robbery system. It is a little pack that contains a GSM module and a few explicit parts. The sys-tem can be associated with by a SMS from the owner, which everything considered readies the microcontroller to butcher the vehicle, get in-structure about the vehicle's present district or more. We unequivocally see that the improvement of a nation should be conceivable in a general sense through basic improvement of all class of people. Beginning now and into the not unbelievably far-removed this vehicle following structure which shows to drive in like manner as unassuming would help a ton in lessening down expenses, ensuring the security of the vehicle be it 2 or 3 or 4 or in a general sense higher wheeled vehicles.

\section{SYSTEMS USED IN TRANSPORTATION}

Notwithstanding the different sorts of progress that have been open to beginning late with square vehicle thefts and following it, the sensibility of these structures have not reduced vehicle robberies by a generally charming rate. In like way two or three security and following structures are proposed to help attempts with beast number of vehicles for ocean control the experts. An ocean control the store up structure can oblige the expense and exertion of experts to complete street assignments inside an irrelevant time. Besides, assignments can be made systems for bleeding edge subject to current vehicles zone.

Thusly, focal social affair the experts is major to mammoth leaves to meet the fluctuating necessities of clients and to improve the bit of breathing room. Notwithstanding, there are still some security openings where these sorts of progress don't keep a vehicle from thievery, don't recuperate it and don't pound in the clients to know the status of their vehicles. They can't empower the proprietor to visit with the vehicle, offering little gratefulness to whether the proprietor is sure that his vehicle is taken.

There exist two sorts of contraptions for vehicles for following, robbery guaranteeing and achievement from thievery. These are,

1. GPS Tracking contraptions for vehicles: These structures give following of vehicle locale dependably. If there should be an occasion of thefts these structures won't have the decision to stop the vehicle considering the way wherein that these frameworks can on a fundamental level give the GPS co-ordinates of the vehicle genuinely. There is no program for robbery region or a contraption squashed in with the structure to stop the vehicle. One of such GPS channels through that is utilized in India is called MapMyIndia and it costs INR 15000

GPS following near Central Locking and Immobilizer: These structures give GPS following mysteriously as systems to stop the vehicle by utilizing a focal locking and immobilizer instrument. These structures have the circuit to see robbery zone and to shield the theft from occurring. The most when all is said in done utilized GPS following near Central Locking and Immobilizer are Auto Cop which costs INR 16000 and 3Detrack which costs INR 18000. These frameworks are the most broadly utilized structures worldwide and are not utilized much in India in setting on the central expense.

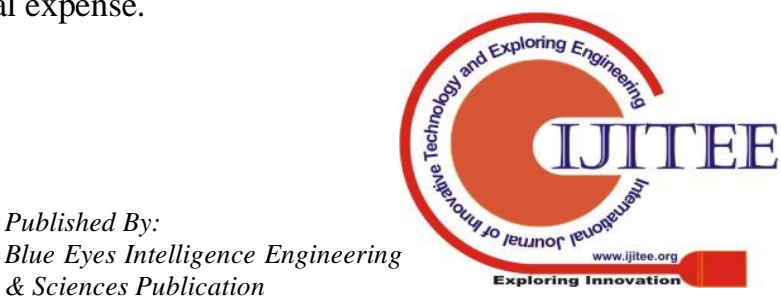


Riches Sports affiliations that age vehicles like BMW, Mercedes, Lamborghini, Porsche, and so forth have pre-content with undermining with thievery and following structures. All fundamental vehicle affiliations don't have such structures.

Considering all the creation study and the Market study the structure made ought to have improved sufficiency, reduced power use, diminished cost and size, improved accuracy, brief and simple to utilize and installable in all vehicles (with fuel injectors) over the current or explored structures open.

\section{ANTI THEFT SYSTEM}

The principal objective of the counter burglary structure for vehicles is to set up a relationship among vehicle and the customer. The made alliance adornments with the vehicle to fortify the customer in condition concerning burglary and the customer can stop the vehicle in the wake of sending a heading. The structure should be humbler with the objective that it will everything considered be put at a zone where a criminal can't see it and everything considered the security of the vehicle and the suffering thought of the system isn't undermined. The degree of the appraisal as sweeps for after: - To execute structure to give vehicle following ceaselessly.

- Design a structure to see thievery and tell customer of burglary.

To enough execute the structure adroitly a GPS Antenna, GPS+GSM Module, a Microcontroller and a Relay circuit will be required. Figure 3 shows the structure of the system. In this structure, a GPS Antenna is used to demand suffering GPS co-ordinates of the vehicle.

A GPS+GSM Module (SIM808 Module) is used to finish the extraction of GPS co-ordinates got from GPS radio wire. GSM part of the SIM808 Module is used for sending the GPS co-ordinates and the bearing message about the robbery to the customer by structures for SMS Messages and for getting headings from the customer to start or stop the vehicle. Vehicle is stopped using a hand-off circuit which can cut the stock to fuel injector from the battery. Move circuit used is executed using a Hercules Motor driver IC. This IC has high information run and gives support from over voltage/over current. In like manner this driver is checked to use for vehicle battery with the objective that the battery doesn't get hurt by any voltage/rehashing structure changes. The microcontroller is the most huge bit of the structure and controls the entire advancement while restricting through with SIM808, GPS Antenna and the Relay circuit.

SIM808 Module expels the GPS co-ordinates from the GPS recieving wire and the cut back scale controller changes over the GPS co-ordinates isolated into a structure that can be used for signal planning. In case robbery is seen, the microcontroller close by SIM808 sends the censure SMS Message to the customer and gets the headings by points of view for answer got from the customer. The Microcontroller changes over the sign which is then applied to the exchange circuit. The SMS message and GPS co-ordinates is sent by SIM808, GPS gathering contraption identified with Microcontroller.

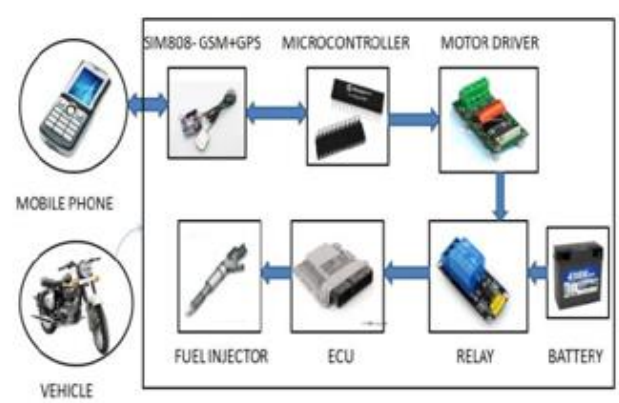

Fig.3. Block diagram of the system

The system requires the following I/O functions:

Conversion of GPS co-ordinates got by GPS radio wire (GPS part of SIM808) into content structure that can be showed up by methodology for a SMS message.

Conversion of SMS Message (GSM part of SIM808) into electrical sign for controlling hand-off and sending of SMS message utilizing Microcontroller and SIM808

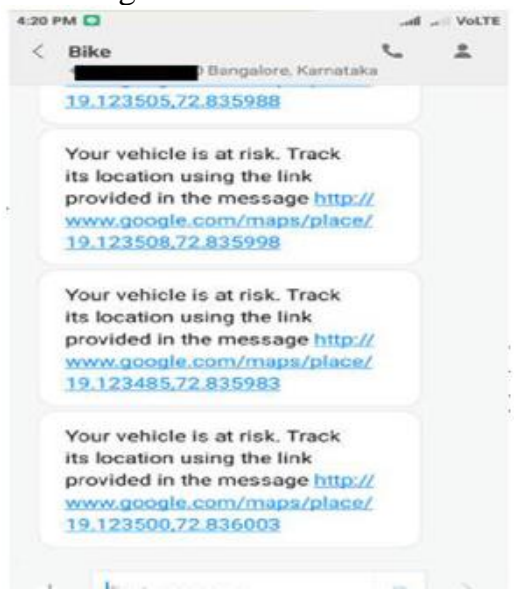

FIG.5. SMS WITH GPS CO-ORDINATES OF VEHICLE

\section{ALGORITHM FOR THEFT DETECTION}

For thievery seeing confirmation, estimation appeared in figure 4 is utilized. At whatever point vehicle begins, structure will send a SMS to the proprietor. On the off chance that vehicle use was unapproved, proprietor would then have the decision to answer with a book SMS 'Stop' to butcher the vehicle.

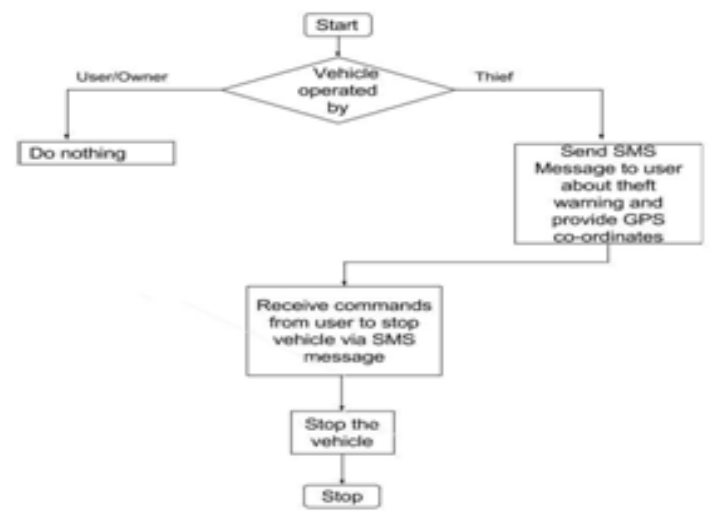

Fig.4. Algorithm for theft detection 


\section{Smart Key Security for Vehicles Thefting}

\section{V.RESULT}

The improvement was made to execute the structure persistently on a Battery of a vehicle (Bike) while putting the framework inside the vehicle to such an extent, that it isn't irrefutable to the guilty party. Testing of the framework was done and the structure reacted by sending a notice SMS message to the client when there was unapproved improvement of the vehicle. The client got a SMS message which had the alarm message and GPS co-ordinates. The client sent a SMS message to stop the vehicle and the framework reacted to this message by moving the stock to the battery and in like way the vehicle wrapped $\mathrm{u}$

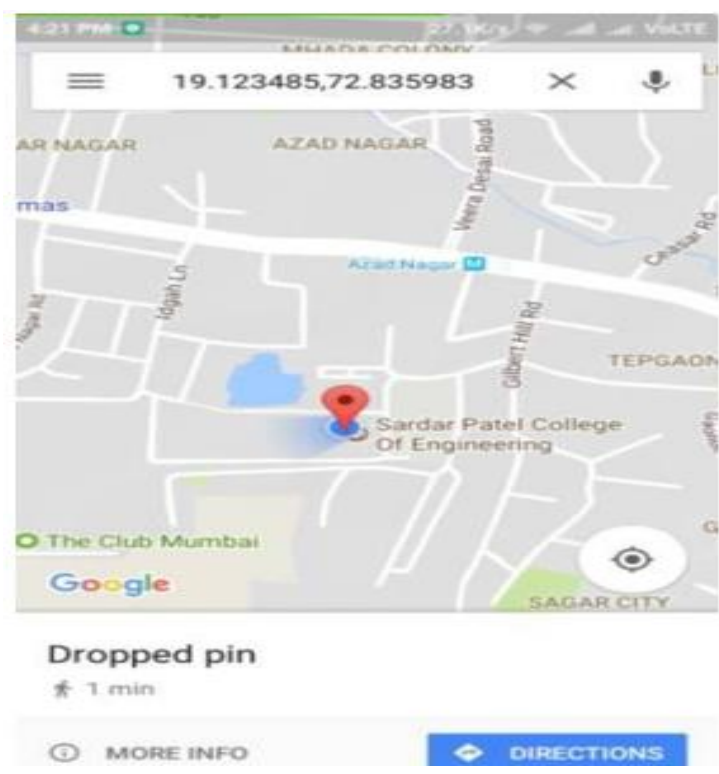

Fig.6. Location in Google maps.

\section{Conclusion}

The system developed effectively provides an application of connected devices or Internet of things in Transportation. The system includes a Combined GPS+GSM Module which can track the location of the vehicle via the GPS antenna implanted in the vehicle. Thus, this system is an integration of several modern embedded and communication technologies. This makes the system very cheap since these are simple and open source technologies. Also the system is very compact. Security standards are maintained by mobile network providers hence security of the network is very good. This makes the system suitable for the market since it is cheaper than other anti-theft systems available. Also it is user friendly since a simple 'Stop' SMS turns the vehicle off. Along with tracking and theft prevention, this systemcan also provide more applications like condition monitoring, vehicle control, fleet management, traffic management, smart parking and vehicle safety by using various sensors like speed sensor, alcohol sensor, proximity sensor and other sensors to get the data about condition and performance of vehicle and the driver. Thus, this system is very useful and can be used in all aspects of transportation system.

\section{REFERENCES}

1. Luigi Atzori, Antonio Iera, Giacomo Morabito, 'The Internet of Things: A survey', Computer Networks, Elsevier.
2. Dave Evans, 2011, 'The Internet of Things-How the Next Evolution of the Internet is Changing Everything', Cisco Internet Business Solutions Group (IBSG).

3. Kashif Naseer Qureshi, 2013, 'Survey on Intelligent Transportation Systems', Middle-East Journal of Scientific Research 15 (5): 629-642, 2013 ISSN 1990-9233 @ IDOSI Publications.

4. Newman-Askins, Raechelle and Ferreira, Luis and Bunker, Jonathan $\mathrm{M}$, 'Intelligent transport systems evaluation: From theory to practice', Proceedings 21 st ARRB and $11^{\text {th }}$ REAAA Conference.

5. Mashood Mukhtar, 2015, 'GPS based Advanced Vehicle Tracking and Vehicle Control System', I.J.Intelligent Systems and Applications, 03, 1-12.

6. Abid khan, Ravi Mishra, 2012, 'GPS - GSM Based Tracking System', International Journal of Engineering Trends and Technology- Volume3 Issue2.

7. G.S.Prasanth Ganesh, B.Balaji, T.A.Srinivasa Varadhan, 2011, 'Anti-Theft Tracking Sys-tem for Automobiles (AutoGSM)', IEEE International Conference on Anti-Counterfeiting, Security and Identification.

8. Stefan Schulte, Philipp Hoenisch, Kristof Kipp, Daniel Burgstahler, Sven Abels, Giuseppe Liguori, 2016, \&quot;A Service Framework for Smart Mobility Scenarios", IEEE International Conference on, pp. 17-24, 2016, ISSN 2329- 6453

9. Rahat Ali Khan, Shakeel Ahmed Shah, Muhammad Abdul Aleem, Zulfiqar Ali Bhutto, Asad Ali Shaikh, Muhmaad Aslam Kumbhar, 2012 , 'A Solution for Smart Transportation', VOL. 3, NO. 4, ISSN 2079-8407 Journal of Emerging Trends in Computing and Information Sciences.

10. John A. Stankovic, 2014, 'Research Directions for the Internet of Things', IEEE Internet Of Things Journal, Vol. 1, No. 1, February.

11. Li Da Xu, Senior Member, Wu He, and Shancang $\mathrm{Li}$, 'Internet of Things in Industries: A Survey', Ieee Transactions On Industrial Informatics, Vol. 10, No. 4, November.

12. Miss. Pratibha, L. Yadav, Prof. Sanjay S. Badhe, Prof.Santosh G. Bari, 2016, 'Study and Literature Survey for Safety Applications: Intelligent Transport System (ITS)', 5940 International Journal of Advanced Research in Computer and Communication Engineering Vol. 5. 